\title{
Massive Barium Sulfate Aspiration in the Bronchial Tree
}

\author{
Kosuke Ohkuma, Takeshi Saraya, Naoki Tsujimoto and Hajime Takizawa
}

Key words: barium sulfate, aspiration

(Intern Med 54: 2081, 2015)

(DOI: 10.2169/internalmedicine.54.4829)

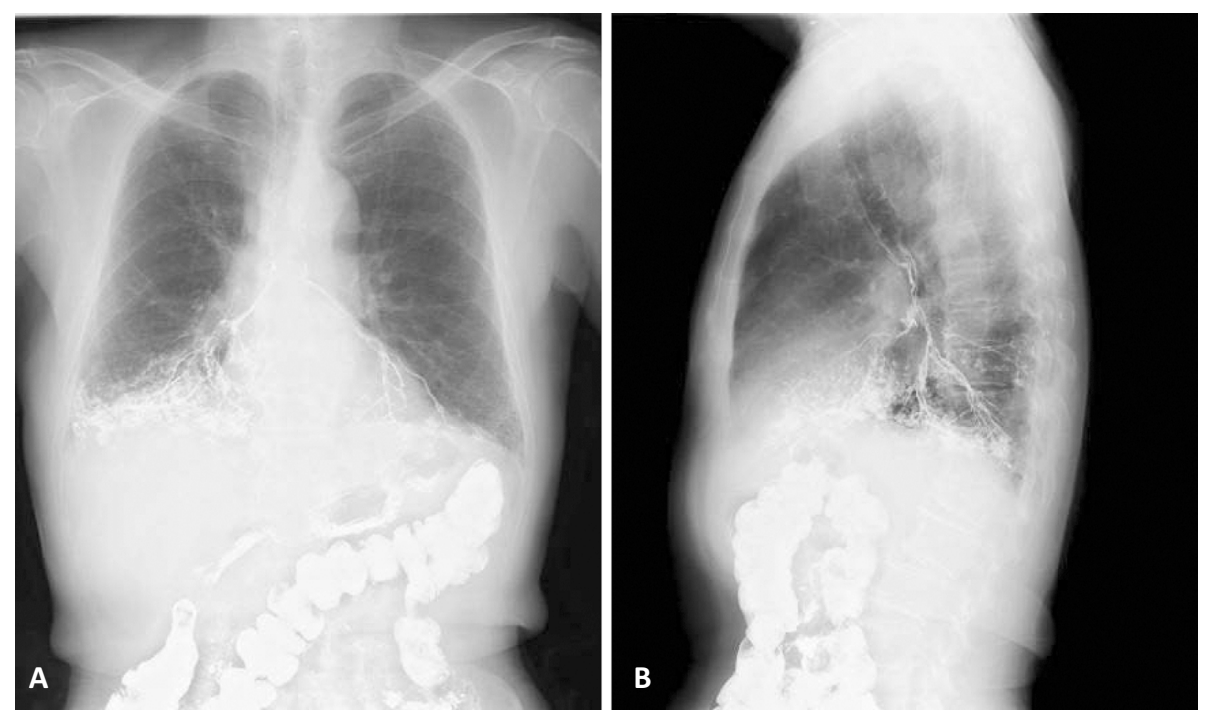

Picture.

A 75-year-old man was referred to our respiratory department from his local hospital due to the massive aspiration of barium sulfate during his annual checkup with esophagogastroduodenography. He had suffered from a subdural hematoma seven years previously, but had no apparent history of aspiration pneumonia and/or swallowing disorders. The physical examination indicated coarse crackles in the bilateral lower lung fields. A chest X-ray taken 2 hours after the aspiration (Picture) showed that the barium sulfate was located in the segmental and sub-segmental branches of the bronchial tree of the lower lobes bilaterally, as well as in the smaller airways, thus resulting in a tree-in-bud appearance. In contrast to hydrosoluble contrast media (e.g., gastrografin), barium sulfate is not irritable to the lung (1). How- ever, physicians should be aware that massive aspiration may sometimes be fatal, especially in elderly patients, who initially present with a rapid progressive cough, followed by fever, tachypnea, and hypotension (2).

The authors state that they have no Conflict of Interest (COI).

\section{References}

1. Voloudaki A, Ergazakis N, Gourtsoyiannis N. Late changes in barium sulfate aspiration: HRCT features. Eur Radiol 13: 2226-2229, 2003.

2. Fruchter O, Dragu R. Images in clinical medicine. A deadly examination. N Engl J Med 348: 1016, 2003.

Department of Respiratory Medicine, Kyorin University School of Medicine, Japan

Received for publication December 26, 2014; Accepted for publication January 13, 2015

Correspondence to Dr. Takeshi Saraya, sara@yd5.so-net.ne.jp

(C) 2015 The Japanese Society of Internal Medicine Journal Website: http://www.naika.or.jp/imonline/index.html 